\title{
Research on the Path of Manufacturing Enterprises Supply Chain Integration from the Configuration Perspective
}

\author{
Hongxiong Yang and Yunpeng Wang *
}

Citation: Yang, H.; Wang, Y.

Research on the Path of

Manufacturing Enterprises Supply

Chain Integration from the

Configuration Perspective. Processes

2021, 9, 1746. https://doi.org/

$10.3390 /$ pr9101746

Academic Editors: Jun-Wei Lim and Worapon Kiatkittipong

Received: 2 September 2021

Accepted: 26 September 2021

Published: 29 September 2021

Publisher's Note: MDPI stays neutral with regard to jurisdictional claims in published maps and institutional affiliations.

Copyright: (C) 2021 by the authors Licensee MDPI, Basel, Switzerland. This article is an open access article distributed under the terms and conditions of the Creative Commons Attribution (CC BY) license (https:/ / creativecommons.org/licenses/by/ $4.0 /)$.
School of Management, Tianjin University of Technology, Tianjin 300384, China; yanghongxiong@email.tjut.edu.cn

* Correspondence: Wangyunpeng0926@163.com; Tel.: +86-152-3050-1075

\begin{abstract}
In digital transformation and development, supply chain integration has become a key strategy to improve supply chain synergy efficiency and enhance enterprise competitiveness. Based on the survey data of 185 manufacturing enterprises in Tianjin, the fuzzy set qualitative comparative analysis (fs QCA) method is used to explore the synergistic mechanism of government policy, supply chain partnership, information sharing, risk avoidance, and intelligence degree on supply chain integration and the interaction among them. The results show that: (1) a single factor does not constitute a necessary condition for promoting supply chain integration, but the formation and development of supply chain partnership plays a universal role in promoting supply chain integration; (2) the "multiple concurrent" of five factors constitute the diversified configuration of a driving supply chain integration path, that is, the driving supply chain integration path has the characteristic of "all roads lead to the same destination"; (3) there is a "sharing" type, a "cooperative" type, and a "cooperative-sharing" type three equivalent path, whereby the formation of supply chain partnership can enhance the trust between manufacturing enterprises and suppliers and customers, increase the transaction frequency of upstream and downstream enterprises, and improve the cooperation efficiency. The utility model can effectively reduce the "long whip" problem caused by the information asymmetry, and improve the operational efficiency and stability of the whole supply chain. The purpose of this study is to inspire manufacturing enterprises in the context of digital supply chain integration to improve the collaborative efficiency of the supply chain.
\end{abstract}

Keywords: manufacturing enterprise; supply chain integration; integration path; collaborative efficiency; qualitative comparative analysis of fuzzy sets

\section{Introduction}

In today's digital trend of information development, enterprises must keep up with the degree of unceasing enhancement, and improvement of the supply chain in the development of intelligent collaborative efficiency has become a hot spot in the industry. For enterprises to keep up with current developments, it is necessary to explore more agile and efficient supply chain integration pathways to promote the intelligent coordination of the supply chain efficiency. Based on this, more and more enterprises are paying attention to supply chain integration. Supply chain integration can make the enterprise more collaborative via cooperation between the customers and suppliers, and to some extent, can realize the resource sharing. To enhance the competitiveness of the supply chain and promote the improvement of enterprise operating performance [1], this is the key to gain a competitive edge in the complex market environment. However, in a dynamic and complex environment, the primary concerns of enterprises are which supply chain integration strategy to adopt and how to integrate it [2], as the study of manufacturing in the supply chain integration path is of extremely practical significance.

In recent years, many types of studies on supply chain integration have been carried out in academia and have achieved fruitful results. To sum up, supply chain integration is 
a management strategy of manufacturing enterprises that enables enterprises to carry out higher-level cooperation through cooperation and coordination to improve the competitiveness and operating benefits of enterprises in the supply chain [2-5]. There are many factors affecting supply chain integration, including government support, supply chain partnership, information sharing, risk avoidance, etc. Different scholars have also carried out relevant studies on how these factors affect supply chain integration. Zeng Mingang et al. [6] investigated 180 manufacturing enterprises in the Pearl River Delta region and found that government policies can indirectly promote supply chain integration by influencing environmental uncertainty. Pan Ancheng et al. [7] studied a project team based on the cultural background of reason and found that a close partnership is an effective means to improve the integration of the supply chain. From the perspective of reducing the bullwhip effect, Zhang Wei et al. [8] pointed out that in the supply chain, information transmission and sharing can help improve the performance of the whole supply chain. Wang Li [9] believes that the optimization and integration of the manufacturing supply chain can provide effective help for enterprises to avoid risks, improve their profitability and speed up capital turnover. However, at present, Chinese enterprises are gradually developing towards the direction of digitalization, and the degree of intelligence of enterprises is deepening, so the degree of intelligence of enterprises in the supply chain has become a new factor that may affect the integration of supply chain. Huo Yanfang et al. [10] pointed out that if manufacturing enterprises want to gain advantages in market competition, the most important thing is to grasp the current intelligent manufacturing environment and design a convenient and effective supply chain. Throughout the past, the research of supply chain integration found that most still focus on the integration of various factors of a single probe. The relative lack of systematic analysis of the supply chain integration factors and the mechanism of interaction between various factors and the path of research make it hard to get an effectively suitable supply chain enterprise integration path to attract manufacturing enterprises in the supply chain integration. In particular, few scholars introduce how to integrate the supply chain of manufacturing enterprises under the background of digitalization so that it can better adapt to the requirements of intelligent manufacturing on the supply chain function. Therefore, this article introduces integrity research; the integration of the existing factors includes intelligent degree study, the integrated use of literary analysis, a questionnaire survey method, and a fuzzy qualitative comparative analysis method to build the research model of manufacturing enterprise supply chain integration, providing a combination of quantitative and qualitative analysis to explore the integration of the supply chain paths. To improve the competitiveness of the supply chain of manufacturing enterprises and the overall collaborative efficiency under the background of digitization, the optimal combination of factors conducive to supply chain integration is sought.

\section{Literature Review}

\subsection{The Nature of Supply Chain Integration}

Supply chain integration is the focus of supply chain management. It improves the operational performance of the supply chain by optimizing the behavior process, organization, business process, and management links related to the supply chain by core enterprises [11]. Scholars at home and abroad have conducted a lot of studies on supply chain integration. Malonii and Benton [3] defined supply chain integration as a higher level of cooperative management between supply chain partners to provide customers with higher value and improve competitive advantages, and divided supply chain integration into internal integration and external integration for the first time. Huo et al. [4] pointed out in their studies that supply chain integration reflects enterprises' ability to formulate strategic alliances, restructuring resources, build seamless processes, and exchange and share information. $\mathrm{Xu}$ Ke [5] believes that supply chain integration is strategic cooperation of information integration, resource coordination, inter-organization interconnection, and process management. Generally, a supply chain is composed of suppliers, manufacturers 
and customers. Therefore, Flynn et al. [2] divides supply chain integration into three dimensions: customer integration, supplier integration, and internal integration. Among them, the integration of customers and suppliers is called external integration, which refers to the synchronization of strategic cooperation and process cooperation among enterprises by establishing partnerships with core enterprises in the supply chain. Internal integration refers to the synchronization of strategy, operation, and process through internal collaboration to meet customer needs.

The comprehensive research of scholars found that although different scholars put different emphasis on the nature of supply chain integration, they all pointed to its role in enterprise strategic cooperation and process management. Few scholars have systematically explored and studied the complex process of synergistic action among factors promoting supply chain integration. Therefore, based on previous studies on influencing factors of supply chain integration and the current status of digital transformation of Chinese manufacturing enterprises, this paper comprehensively studies the influence mechanism of government policy, supply chain partnership, information sharing, risk avoidance and intelligence degree on the supply chain integration path of manufacturing enterprises. In order to enhance the competitive advantage of manufacturing enterprises in the process of digital development and improve the efficiency of cooperation between manufacturing enterprises and other enterprises in the supply chain, this paper studies the supply chain integration path from the two aspects of internal integration and external integration.

\subsection{Internal Factors of Supply Chain Integration}

By analyzing many studies, we found that integration of internal factors of supply chain manufacturing facilitates better cooperation with external suppliers to meet customer demand and between different departments using the integration methods. This allows faster interaction of internal information and the optimizing of enterprise coordination to actively avoid risks, improve their stability and maintain competitive advantages. First of all, from the perspective of information integration, $\mathrm{Xu}$ et al. [12] explained the importance of information exchange and sharing between partners by comparing whether information sharing has fluctuations in orders and changes in safe stock between manufacturers and sellers. Zhou Sihua and Wan Guohua [13] found that the improvement of information capability in supply chain enterprises can significantly positively affect supply chain integration. Phillip and Wendell [14] argue that information communication is the key to maintaining supply chain partnerships, and the existence of such relationships can reduce supply chain integration costs and improve supply chain integration efficiency. Moreover, information exchange between enterprises can have a positive impact on organizational capability and supply chain operational performance through supply chain integration [15]. Secondly, from the perspective of risk avoidance, risk avoidance refers to the decisionmaking behavior that enterprises choose to avoid risks because they are afraid of risks. Pure risks and environmental fluctuations will reduce the overall benefits of the supply chain [16], so it is necessary to study the impact of risk aversion on supply chain integration. Based on the study of supply chain risk management on the performance of commercial circulation enterprises, Wu Qiang et al. [17] found that risk avoidance, risk sharing, and risk transfer in supply chain risk management have a significant positive impact on enterprise performance. Weingarten et al. [18] discussed the role of risk and risk management practices in promoting the success of supply chain integration from a relational perspective and made it clear that the adoption of risk avoidance behavior can promote the success of supply chain integration. The goal of risk avoidance is to reduce the complexity and uncertainty of the supply chain system through supply chain integration, to significantly improve the effectiveness of the supply chain system [19]. Finally, from the perspective of intelligent degree, current scholars do not study the relationship between the degree of intelligent manufacturing and the supply chain integration path, but with the advent of the era of the digital economy, the Internet and the rapid development of artificial intelligence, as the 
intelligent mode of production is more popular with consumers, intelligent manufacturing transformation has become the trend of the times. Zhou Jiajun et al. [20] observed from the perspective of technological foundations that intelligent manufacturing technology is a manufacturing behavior that realizes product design, manufacturing, management, and maintenance through humanoid behavior operations-such as perception and humancomputer interaction based on information technology and artificial intelligence, to realize the integration of the two. The development of the intelligent manufacturing industry also requires the corresponding improvement of intelligent supply chain management systems to a certain extent. Barton et al. [21] pointed out that the key to creating a good supply chain is the improvement of reaction ability and adaptation to high-level intelligent system integration and management ability. It can be seen that the introduction of artificial intelligence technology into supply chain management, the creation of intelligent supply chain management systems, and the use of artificial intelligence and big data analysis technology to explore supply chain management data can improve management efficiency and reduce management costs. Therefore, this paper takes information sharing, risk avoidance, and intelligence degree as internal factors driving supply chain integration.

\subsection{External Factors of Supply Chain Integration}

The research on external influencing factors of supply chain integration can help enterprises get more help in the new development pattern of double circulation and improve the cooperation quality of supply chain partner enterprises. Reviewing previous studies, it can be seen that both government support and supply chain partners have a certain impact on supply chain integration [22,23]. Governments can often influence the industrial structure by allocating resources, and biased government policies will have a lasting impact on the business environment of enterprises [24]. Zeng Mingang, Wu Shaobo et al. [23] selected 251 manufacturing supply chains in Guangdong province to study their integration relationship and found that government policies can play a role in supply chain integration by affecting environmental uncertainty, and it has a significant positive impact on supply chain integration. Zeng Mingang [6] used empirical research to show that customer trust, supplier trust, customer integration, and supplier integration are all significantly affected by government support. Dou Chao et al. [25] pointed out that big customers with government backgrounds can be recognized by the capital market, which can significantly improve the valuation level of enterprises and show their competitive advantages and value. Liu Minghua et al. [26] studied the data of 218 upstream and downstream enterprises of the supply chain and found that partnership has a significant positive impact on supply chain integration. Ye Fei and Xu Xuejun [27] studied the degree of trust, relationship commitment, information sharing, and operational performance among enterprises in the supply chain, and found that trust can positively affect the relationship between relationship commitment, information sharing, and operational performance. Feng Hua et al. [28] believe that sharing information, complementary resources, and creating a reliable transaction environment among supply chain partners are conducive to the integration of nodal enterprises' business activities, to reduce opportunistic behaviors and transaction costs. To sum up the above research findings: the formation and development of any enterprise cannot be separated from the support and assistance of the government. The formation of a good mutual assistance relationship between enterprises and the government can make it easier for enterprises to attract partners, enhance their competitive advantages and promote the integration of the supply chain. In addition, by allying with other enterprises in the supply chain, enterprises can interact and coordinate their resources and information based on mutual trust, which is conducive to the cooperation among enterprises in the supply chain. Therefore, this paper takes government policy and supply chain partnership as external factors driving supply chain integration. 


\subsection{Marginal Contribution of Supply Chain Integration}

Based on the analysis of the above factors affecting supply chain integration, this paper holds that the influence of government policies, supply chain partnerships, information sharing, risk avoidance, and intelligence degree on supply chain integration is not independent but complex. The synergistic effect among all factors makes the traditional regression analysis or structural equation method unable to solve the diversified practical problems of the supply chain integration path. The combination of different integration factors will promote supply chain integration from different aspects. However, the combination of different integration paths will improve the synergy efficiency of the supply chain from different aspects. In this paper, through a questionnaire to collect data and information sharing, we focus on risk aversion and intellectualized degree as internal driving factors of supply chain integration, and government policy and the supply chain partnership as the external driving factors of supply chain integration, constructing the theoretical research framework shown in Figure 1, using fuzzy qualitative research methods of comparative analysis (fs QCA). It reveals how government policy, supply chain partnership, information sharing, risk avoidance, and intelligence drive manufacturing enterprises to conduct supply chain integration, thus providing a theoretical reference for manufacturing enterprises to conduct supply chain integration practice.

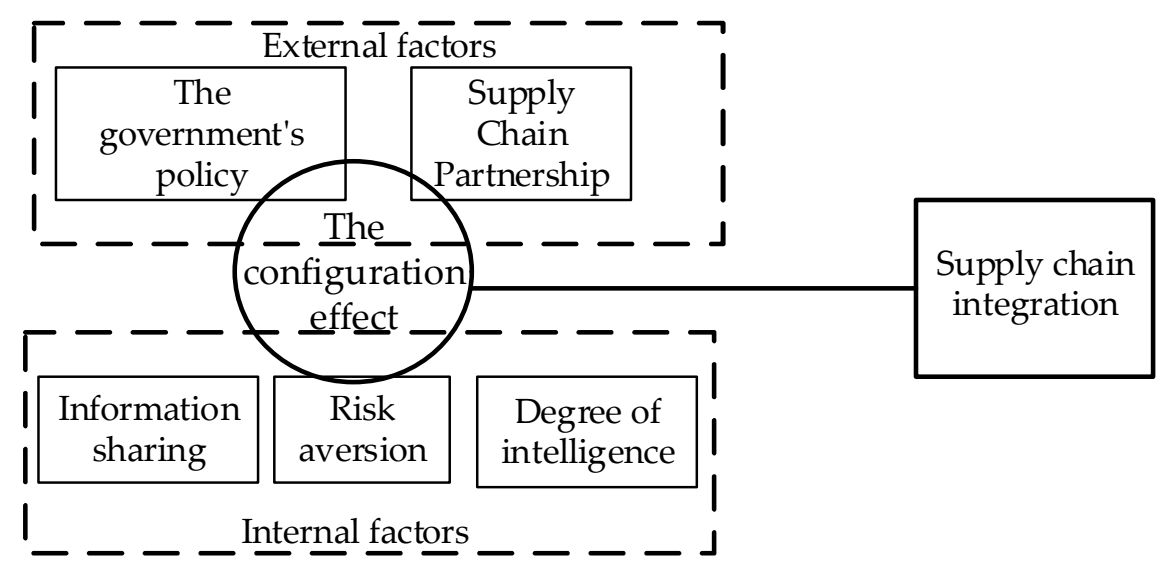

Figure 1. The research framework of supply chain integration theory.

This paper has three marginal contributions to the study of supply chain integration path: First, in terms of integration factors, the paper studies the influence of intelligence degree on supply chain integration under the background of digital development, links this factor with supply chain integration, and discusses the influence of the former on the latter and its mechanism. Second, in terms of research methods, traditional statistical analysis methods such as linear regression and structural equation can only deal with completely corresponding correlation, while the fs QCA method can deal with all kinds of complex asymmetric relations, ensuring the effectiveness of research results. Thirdly, based on the perspective of configuration, this paper adopts the holistic and systematic analysis to empirically test how the configuration of five factors-namely government policy, supply chain partnership, information sharing, risk avoidance and intelligence degree-can better promote the integration of supply chain, and makes a reasonable explanation for the corresponding configuration.

\section{Research Process}

\subsection{Data Collection}

This paper takes the supply chain of manufacturing enterprises in Tianjin as an example, based on the following two points: (1) Tianjin is one of the largest industrial cities in China, and its industrial structure has been constantly upgrading, which is an important carrier of coordinated industrial development in The Beijing-Tianjin-Hebei region; 
(2) In the context of the new normal of economy, the manufacturing industry in Tianjin is developing towards information and intellectualization, with diversified industrial structures and rapid development of emerging industries. The study on the supply chain integration path of manufacturing enterprises in Tianjin will provide a reference for the supply chain integration of manufacturing enterprises in the whole country. In addition, suppliers and distributors are closely linked in the manufacturing industry, which is the industry with the most obvious characteristics of the supply chain and is more typical in the integration of the supply chain. Therefore, this paper takes the supply chain of manufacturing in Tianjin as an example, adopts a questionnaire survey to collect relevant data, and takes 216 manufacturing enterprises in Tianjin as samples. The questionnaire survey started from Mary 2021 to May 2021. A total of 216 questionnaires were sent out, of which 205 were recovered with a recovery rate of $94.91 \%$. After removing invalid questionnaires, 185 valid questionnaires were collected with effective recovery of $90.24 \%$. The main characteristics of the samples are shown in Table 1:

Table 1. Distribution of basic features of samples $(\mathrm{N}=185)$.

\begin{tabular}{|c|c|c|c|}
\hline Sample Characteristics & The Basic Information & Sample Size & Specific Gravity (\%) \\
\hline \multirow{3}{*}{ The enterprise-scale } & A large enterprise & 43 & $23.24 \%$ \\
\hline & Medium-sized enterprise & 87 & $47.03 \%$ \\
\hline & Small and micro enterprises & 55 & $29.73 \%$ \\
\hline \multirow{7}{*}{ The enterprise type } & Agriculture and sideline, food, tobacco, and alcohol & 15 & $8.11 \%$ \\
\hline & Textiles and Apparel & 13 & $7.03 \%$ \\
\hline & Mineral, metal processing, and products & 21 & $11.35 \%$ \\
\hline & The pharmaceutical industry & 17 & $9.19 \%$ \\
\hline & Machinery, transportation equipment & 32 & $17.29 \%$ \\
\hline & Communications, electronics, electrical appliances & 39 & $21.08 \%$ \\
\hline & Other manufacturing & 48 & $25.95 \%$ \\
\hline \multirow{3}{*}{ Sources of funding } & Domestic enterprises & 163 & $88.11 \%$ \\
\hline & The foreign capital enterprise & 7 & $3.78 \%$ \\
\hline & The joint venture & 15 & $8.11 \%$ \\
\hline \multirow{4}{*}{ Enterprise establishment year } & 5 years or less & 48 & $25.95 \%$ \\
\hline & 6 to10 years & 59 & $31.89 \%$ \\
\hline & 11 to 15 years & 45 & $24.32 \%$ \\
\hline & 16 years or more & 33 & $17.84 \%$ \\
\hline
\end{tabular}

\subsection{Qualitative Comparative Analysis Method Based on Fuzzy Sets}

The selection of the fs QCA method is mainly based on two considerations: (1) The manufacturing enterprise supply chain integration shared with multiple factors, such as enterprise risk response, the government's policy support, and the information sharing degree of several different fronts due to the different combinations of conditions that form different paths of manufacturing enterprise supply chain integration; each path [29] has different characteristics, corresponding to different types of manufacturing enterprises. Compared with traditional quantitative analysis methods, the fs QCA analysis method can deal with the influence of more antecedent variables on the result variables, so it can better analyze the influence path of the five antecedent variables on the integration results. (2) In manufacturing enterprise supply chain integration, the antecedent and consequent variables are not necessarily sufficient and necessary relationships, such as information sharing in the supplier data sharing, although they help an enterprise to master the supplier's stock information, price, quality, and so on, which is advantageous for the enterprise to make comparisons of different suppliers, choose the best suppliers, and promote enterprises of supply chain integration. However, it is also possible that some suppliers' data information may be faked, making enterprises make wrong choices, resulting in corresponding economic losses, affecting the normal operation of the supply chain, and thus reducing the overall collaborative efficiency of the supply chain. Compared with the traditional statis- 
tical analysis method which can only deal with the complete corresponding correlation, the fs QCA method can deal with all kinds of complex asymmetric relations. The analysis software used below is fs QCA3.0.

\subsection{Measurement of Variables}

The Likert five-point scale was selected to measure all variables. To ensure the reliability and validity of the scale, the measurement of variables was based on the existing mature scale, and a few items in the questionnaire were revised and adjusted according to the needs of the study in the process of the questionnaire predictive test. Among them, the supply chain integration scale of outcome variable comes from Flynn et al. [2], which measures supplier integration, internal integration, and customer integration from three dimensions, including 10 items such as "we track major customers to get feedback". Among the conditional variables, government policies are mainly referred to and adapted from the research of Cai et al. [30] and Chen et al. [31], and measured from three dimensions of policy support, policy adjustment and political relations, including four questions such as "the government helps our enterprises to obtain resources (capital, labor, key raw materials, etc.)". Partnership mainly adopts the views of Morgan and Hunt [32], Kumar and Dissel [33], and is measured from two dimensions of organizational trust and relationship commitment, including nine questions such as "major suppliers share their available inventory level information with us". Risk avoidance mainly adopts the research theories of Li Mingqiang [34] and Yan Cunyan [35], which are measured from three dimensions of risk system, management attitude and coping methods, including three questions such as "the intensity of risk aversion of enterprises". Information sharing comes from Flynn et al. [2], which measures demand, inventory and, supplier data from three dimensions, including five questions such as "We share demand prediction information of related products with major supply chain partners". The degree of intelligence mainly adopts the research of Meng Fansheng and Zhao Gang [36], and is measured from three dimensions of a product, production mode, and intelligent management, including four items such as "intelligent level of enterprise operation and management". Descriptive statistics of outcome variables and conditional variables are shown in Table 2.

Table 2. Descriptive statistical analysis results.

\begin{tabular}{|c|c|c|c|c|c|c|c|c|}
\hline Condition Variables & $\begin{array}{l}\text { The } \\
\text { Mean }\end{array}$ & $\begin{array}{l}\text { The Standard } \\
\text { Deviation }\end{array}$ & GP & SCP & IS & RA & DOI & SCI \\
\hline Government policy & 2.7297 & 0.8652 & 1 & & & & & \\
\hline Supply chain partnership & 3.0775 & 1.0858 & $-0.444^{* *}$ & 1 & & & & \\
\hline Information sharing & 2.9319 & 0.9789 & $0.308^{* *}$ & $-0.576^{* *}$ & 1 & & & \\
\hline Risk aversion & 2.8378 & 0.9787 & $-0.376^{* *}$ & $0.284^{* *}$ & $0.218^{* *}$ & 1 & & \\
\hline Degree of intelligence & 3.5608 & 0.9430 & $-0.437^{* *}$ & $0.156^{*}$ & $-0.147^{*}$ & $0.244^{* *}$ & 1 & \\
\hline Supply chain integration & 3.5130 & 0.7953 & -0.055 & $0.390 * *$ & 0.133 & $0.529 * *$ & $0.218^{* *}$ & 1 \\
\hline
\end{tabular}

Notes: ${ }^{*}$. At the level 0.01 (double-tailed), the correlation is significant *. At the level of 0.05 (double-tailed), the correlation was significant. "GP" means "government policy", "SCP" means "supply chain partnership", "IS" means "information sharing", "RA" means "risk aversion", "DOI" means "degree of intelligence", "SCI" means "supply chain integration".

\subsection{Reliability and Validity Test}

SPSS25.0 was used to test the reliability and validity of the scale [37], and the results are shown in Table 3. Cronbach's $\alpha$ and composite reliability (CR) ranged from 0.897 to 0.938 and 0.763 to 0.973 , respectively. The reliability indexes were all above 0.7 , which met the internal consistency of the scale, indicating the high reliability of the questionnaire [38]. Exploratory factor analysis (EFA) was conducted on the questionnaire, the statistical test (Kaiser Meyer Olkin, KMO) ranged from 0.749 to 0.942 [39], which passed the significance level test of 0.001 . At the same time, six factors with characteristic roots greater than 1 were analyzed, explaining $78.56 \%$ (higher than 50\%) variance, indicating that the study had good structural validity. Confirmatory factor analysis (CFA) of AMOS23.0 scale showed that the model fit degree was high $\left(\chi^{2} / \mathrm{DF}=2.134, \mathrm{RMSEA}=0.0785, \mathrm{IFI}=0.912, \mathrm{TLI}=0.900\right.$, 
$\mathrm{CFI}=0.911)[40,41]$, and the standard factor load was above 0.6 . The average variance extracted (AVE) values of each variable ranged from 0.518 to 0.802 [42], indicating that this study had good aggregation validity.

Table 3. Reliability and validity analysis of variables.

\begin{tabular}{|c|c|c|c|c|c|c|}
\hline Condition Variables & $\begin{array}{l}\text { Target } \\
\text { Item }\end{array}$ & $\begin{array}{l}\text { Load } \\
\text { Factor }\end{array}$ & $\begin{array}{l}\text { Alpha } \\
\text { Value }\end{array}$ & CR & KMO & AVE \\
\hline Government policy & $\begin{array}{l}\text { GP1 } \\
\text { GP2 } \\
\text { GP3 } \\
\text { GP4 }\end{array}$ & $\begin{array}{l}0.923 \\
0.842 \\
0.761 \\
0.873\end{array}$ & 0.912 & 0.913 & 0.816 & 0.726 \\
\hline Supply chain partnership & $\begin{array}{l}\text { SCP1 } \\
\text { SCP2 } \\
\text { SCP3 } \\
\text { SCP4 } \\
\text { SCP5 } \\
\text { SCP6 } \\
\text { SCP7 } \\
\text { SCP8 } \\
\text { SCP9 }\end{array}$ & $\begin{array}{l}0.920 \\
0.896 \\
0.894 \\
0.888 \\
0.911 \\
0.849 \\
0.889 \\
0.888 \\
0.925\end{array}$ & 0.973 & 0.973 & 0.942 & 0.802 \\
\hline Information sharing & $\begin{array}{l}\text { IS1 } \\
\text { IS2 } \\
\text { IS3 } \\
\text { IS4 } \\
\text { IS5 }\end{array}$ & $\begin{array}{l}0.902 \\
0.744 \\
0.858 \\
0.699 \\
0.834\end{array}$ & 0.920 & 0.905 & 0.800 & 0.657 \\
\hline Risk aversion & $\begin{array}{l}\text { RA1 } \\
\text { RA2 } \\
\text { RA3 }\end{array}$ & $\begin{array}{l}0.744 \\
0.721 \\
0.692\end{array}$ & 0.910 & 0.763 & 0.749 & 0.518 \\
\hline Degree of intelligence & $\begin{array}{l}\text { DOI1 } \\
\text { DOI2 } \\
\text { DOI3 } \\
\text { DOI4 }\end{array}$ & $\begin{array}{l}0.922 \\
0.745 \\
0.806 \\
0.843\end{array}$ & 0.897 & 0.899 & 0.810 & 0.691 \\
\hline Supply chain integration & $\begin{array}{l}\text { SCI1 } \\
\text { SCI2 } \\
\text { SCI3 } \\
\text { SCI4 } \\
\text { SCI5 } \\
\text { SCI6 } \\
\text { SCI7 } \\
\text { SCI8 } \\
\text { SCI9 } \\
\text { SCI10 }\end{array}$ & $\begin{array}{l}0.839 \\
0.777 \\
0.755 \\
0.618 \\
0.755 \\
0.633 \\
0.864 \\
0.902 \\
0.877 \\
0.859\end{array}$ & 0.938 & 0.944 & 0.915 & 0.630 \\
\hline
\end{tabular}

Note: "GP" means "government policy", "SCP" means " supply chain partnership", "IS" means "information sharing", "RA" means "risk aversion", "DOI" means "degree of intelligence ", "SCI" means "supply chain integration".

\subsection{Variable Calibration}

According to the fs QCA method, a case belongs to a set, and calibration is the process of assigning membership scores to each case set [43]. The calibration of variables is usually based on existing theoretical knowledge or researchers' experience, and there are three critical points of complete membership, intersection, and complete non-membership on punctuality [44]. The process of transforming variables into sets on $0 \sim 1$ is fuzzy set analysis. Referring to the Likert five-level scale to measure the degree of formalization of organizational structure, " 5 " is set as complete membership, " 3 " as intersection, and " 1 " as complete non-membership, as shown in Table 4: 
Table 4. Variable calibration anchor points.

\begin{tabular}{|c|c|c|c|c|}
\hline \multirow{2}{*}{\multicolumn{2}{|c|}{ Condition Variables }} & \multicolumn{3}{|c|}{ The Anchor } \\
\hline & & \multirow{2}{*}{ 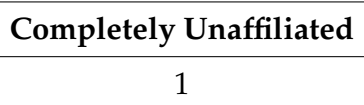 } & \multirow{2}{*}{$\frac{\text { Intersection }}{3}$} & \multirow{2}{*}{$\frac{\text { Full Membership }}{5}$} \\
\hline & Government policy & & & \\
\hline External factors & Supply chain partnership & 1 & 3 & 5 \\
\hline \multirow{3}{*}{ Internal factors } & Information sharing & 1 & 3 & 5 \\
\hline & Risk aversion & 1 & 3 & 5 \\
\hline & Degree of intelligence & 1 & 3 & 5 \\
\hline The results of variable & Supply chain integration & 1 & 3 & 5 \\
\hline
\end{tabular}

\section{Result Analysis}

\subsection{Univariate Result Analysis}

Before configuration analysis, it is necessary to discuss whether a single driving factor is a sufficient and necessary condition for the supply chain integration of manufacturing enterprises. According to Ragin's research, when the consistency is greater than 0.9 , this condition can be identified as a necessary condition for the outcome variable [44]. The analysis results of single factor necessary conditions are shown in Table 5. The results show that all ante-cause conditions of manufacturing enterprises' integration factors are less than 0.9 , indicating that government policy support, supply chain partnership, information sharing, risk avoidance, and intelligence degree are not the necessary conditions for manufacturing enterprises' supply chain integration. This result verified the combination of factors of supply chain integration in manufacturing enterprises, that is to say, the supply chain integration of manufacturing enterprises is a complex system, no single factor has a significant effect, and the supply chain integration path of manufacturing enterprises is multiple.

Table 5. Single-factor necessity analysis results of supply chain integration of manufacturing enterprises.

\begin{tabular}{ccc}
\hline \multirow{2}{*}{ Condition Variables } & \multicolumn{2}{c}{ Supply Chain Integration } \\
\cline { 2 - 3 } & Consistency & Coverage \\
\hline Government policy & 0.521544 & 0.832768 \\
$\sim$ Government policy & 0.736571 & 0.831089 \\
Supply chain partnership & 0.699207 & 0.889444 \\
$\sim$ Supply chain partnership & 0.539776 & 0.743050 \\
Information sharing & 0.617448 & 0.856042 \\
$\sim$ Information sharing & 0.632900 & 0.799856 \\
Risk aversion & 0.646881 & 0.955556 \\
$\sim$ Risk aversion & 0.631510 & 0.755772 \\
Degree of intelligence & 0.807538 & 0.814060 \\
$\sim$ Degree of intelligence & 0.422124 & 0.810900 \\
\hline Note: “" means "not" in logical operation & &
\end{tabular}

Note: " $\sim$ " means "not" in logical operation.

\subsection{Configuration Analysis}

Through truth table analysis, three kinds of solutions are obtained, which are a complex solution, reduced solution, and intermediate solution. Among them, the core conditions appear in both the simplified and intermediate solutions, while the edge conditions only appear in the intermediate solutions [44]. The configuration analysis results obtained through Boolean algebra operation are shown in Table 6. Fs QCA analysis needs set case frequency thresholds and consistency threshold filtering to explain the variables with a sufficient explanation of the former conditions [44]. Among them, consistency represents the proportion of all cases covering the result, and the case frequency threshold refers to the corresponding degree of the set relationship expressed in the case and the solution. 
According to the research of Fiss [45] and Du Yunzhou et al. [46], the consistency threshold is set as 0.8 , the case frequency threshold is set as 1 , and the PRI threshold is set as 0.75 .

Table 6. Configuration of supply chain integration factors.

\begin{tabular}{|c|c|c|c|c|c|}
\hline \multirow{2}{*}{ Condition Variables } & \multicolumn{5}{|c|}{ Supply Chain Integration } \\
\hline & Solution 1 & Solution 2A & Solution 2B & Solution 3A & Solution 3B \\
\hline Government policy & $\bullet$ & 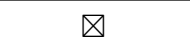 & $\nabla$ & $\nabla$ & • \\
\hline Supply chain partnership & $\bigotimes$ & O & O & O & \\
\hline Information sharing & & & $\bigotimes$ & O & \\
\hline Risk aversion & $凶$ & $\bullet$ & & & \\
\hline Degree of intelligence & 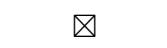 & & $\bullet$ & 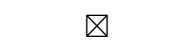 & $\bullet$ \\
\hline Consistency & 0.879171 & 0.992582 & 0.906883 & 0.998173 & 0.998146 \\
\hline Original coverage & 0.28436 & 0.459489 & 0.515984 & 0.26008 & 0.30807 \\
\hline Unique coverage & 0.0925514 & 0.0402256 & 0.120922 & 0.0155342 & 0.0294334 \\
\hline Total consistency & & & 0.883473 & & \\
\hline The total coverage & & & 0.717194 & & \\
\hline
\end{tabular}

Note: represents that the core condition exists; $\bigotimes$ represents the absence of a core condition; $\bullet$ represents the existence of marginal conditions; $\otimes$ represents the absence of marginal conditions; "Blank" indicates that the condition can be present or absent.

The Fs QCA3.0 software shows a group consistency of 5, which is greater than the 0.8 threshold factors combination of manufacturing enterprise supply chain integration, as shown in Table 5. Although the integration factors contained in each set of results are different, each configuration can promote the supply chain integration of manufacturing enterprises to the same extent. Therefore, each combination of integration factors is equivalent. According to the total coverage, it can be concluded that the five integrated configurations explain about $71.72 \%$ of the supply chain samples of manufacturing enterprises. The consistency indexes of the five configurations were $0.879171,0.992582,0.906883,0.998173$, and 0.998146 , respectively, showing a high consistency level. The five configuration results in Table 5 show that the original coverage is $0.2844,0.4595,0.5160,0.2601$ and 0.3081 respectively, indicating that solutions $1,2 \mathrm{~A}, 2 \mathrm{~B}, 3 \mathrm{~A}$ and $3 \mathrm{~B}$, the ratio of 5 configuration cases to all manufacturing supply chain integration cases were $28.44 \%, 45.95 \%, 51.60 \%, 26.01 \%$ and $30.81 \%$, respectively. The unique coverage is the ratio of manufacturing enterprise supply chain integration cases explained by a single configuration after excluding common cases of other configurations. The unique coverage of five configurations is $0.0926,0.0402$, $0.1209,0.0155$, and 0.0294 , respectively. Comparatively, solution 2B configuration has the highest coverage.

Under the complex action of government policy, supply chain partnership, information sharing, risk avoidance, and intelligence degree, supply chain integration presents five realization configurations, namely, configurations 1, 2A, 2B, 3A, and 3B. According to the existence or absence of different elements in each configuration, and whether they are core conditions or edge conditions, the five configurations obtained by running fs QCA are divided into the following three types of supply chain integration paths of manufacturing enterprises:

Path 1: No matter whether other conditions exist or not, as long as information sharing exists as the core condition and government policies are assisted as the marginal condition, supply chain integration can be effectively promoted and collaborative efficiency among enterprises can be improved (configuration 1).

In configuration 1, the consistency level is 0.8792 and the unique coverage is 0.0926 . In this configuration, the manufacturing enterprise supply chain integration configuration 1 shows that, even if supply chain partnership (core condition) does not exist, as long as there is information sharing as core condition and government policy as edge condition, supply chain integration can be promoted even if there is no risk avoidance and intelligence degree. We named this path "sharing". This shows that in the process of promoting supply chain integration, information sharing plays a central role, and government policies provide a 
complementary role. Good information sharing can effectively reduce the distortion of supply and demand information caused by a bullwhip effect and promote the visualization of supply chain. In addition, according to the study of Flynn et al. [2], the relationship between information sharing and the supply chain integration promotes each other and spirals upward. Effective exchange of information between supply chain partners, on the one hand, to promote the cooperation between enterprises, to enhance the degree of trust between them, on the other hand, supply chain integration is the integration of all enterprise supply chain for the entire supply network, it will inevitably increase the connection between the various enterprises, to promote the degree of information sharing between them, improve supply chain reaction speed. Enterprises with government support can better attract partners and improve their competitive advantages [25]. Information sharing enhances between suppliers, manufacturers, and customers to a understanding of each other's needs, inventory, improves the production efficiency and inventory turns, government support for the more stable development of enterprises laid a good foundation, so they can effectively promote the integration of the supply chain, improve the quality of cooperation between enterprises, enhance the stability of the supply chain.

Path 2: Supply chain partnership exists as a core condition, and risk aversion exists as a marginal condition, which can promote supply chain integration (configuration $2 \mathrm{~A}$ ), or supply chain integration can be promoted as long as supply chain partnership exists as the core condition and intelligence degree exists as the edge condition (configuration 2B).

In configuration $2 \mathrm{~A}$ and $2 \mathrm{~B}$, the consistency level is 0.9926 and 0.9069 , and the unique coverage is 0.0402 and 0.1209 , respectively. In this path, manufacturing enterprise supply chain integration configuration solution $2 \mathrm{~A}$ shows that whatever information sharing (core conditions) and risk aversion (edge conditions) exists or not, as long as there is as a condition of a core of supply chain partnership and as a condition of the edge of intelligent degree, even if the lack of government policy, can also promote the integration of the supply chain. Solution 2B shows that whether risk avoidance (edge condition) exists or not, supply chain integration can be promoted even without government policies and information sharing as long as there is supply chain partnership as the core condition and intelligence degree as the edge condition. We named this path "cooperative", this means that enterprises can also promote supply chain integration by relying on supply chain partnership as the core condition and the existence of risk avoidance or intelligence degree as the edge condition. This is because the partnership is the relationship between different enterprises to jointly invest relevant resources to achieve business objectives, to achieve the goals set by each other [47]. Through establishing supply chain partnerships, enterprises can reduce operating costs, disperse operating risks and improve production efficiency. Through the sharing of key resources between supply chain partners, the competitive position of enterprises can also be improved [27]. Meanwhile, risk avoidance can reduce the complexity and uncertainty of the supply chain system and significantly improve the effectiveness of the supply chain system through supply chain integration [19]. The key for manufacturing enterprises to deal with the current complex business environment is to grasp the opportunity of intelligent manufacturing and create an agile and efficient supply chain [4]. The level of intelligence determines the response speed of the supply chain. The agility and efficiency of the supply chain can effectively shorten the response time of upstream and downstream enterprises of the supply chain and improve the collaborative efficiency of the supply chain. Therefore, either the combination of supply chain partnership and risk avoidance or the combination of supply chain partnership and intelligence degree can promote the supply chain integration of manufacturing enterprises, to promote collaborative development among enterprises.

Path 3: Regardless of the presence or absence of government policies and intelligence, enterprises can effectively promote supply chain integration through the existence of supply chain partnerships and information sharing as core conditions (configurations $3 \mathrm{~A}$ and 3B). 
The consistency level of configuration $3 \mathrm{~A}$ and $3 \mathrm{~B}$ is high in the three configurations, 0.9982 and 0.9981 , respectively, but the unique coverage is low, 0.0155 and 0.0294 , respectively. In this path, solution $3 \mathrm{~A}$ shows that supply chain partnership and information sharing are core conditions, risk avoidance is optional. Solution 3B shows that all other factors exist except risk aversion. This means that regardless of the presence or absence of government policies and intelligence, enterprises can effectively promote supply chain integration through the existence of supply chain partnerships and information sharing as core conditions. We named this path "cooperative-sharing." The study of Li and Lin [48] proved that the level and quality of information sharing among supply chain partners are positively influenced by the degree of trust. As for the information-sharing behavior of manufacturing enterprises, trust is the key factor for information sharing among members when there is no constraint or norm to regulate the behaviors of members. If enterprises can share profits in the process of information-sharing interaction, they will establish a good trust relationship. The establishment of this relationship can effectively promote the information sharing behavior between the supply chain partners and enhance the stability of the supply chain. This means that the formation of supply chain partnership can promote information sharing, improve the quality and level of shared information, and it is complementary to information sharing. Therefore, enterprises with two core conditions of supply chain partnership and information sharing can also effectively promote supply chain integration and improve the collaborative efficiency of the whole supply chain.

\subsection{Robustness Analysis}

To ensure the robustness of the configuration, the frequency threshold was set to 2, the consistency threshold remained unchanged, and the data was run again. The results only changed slightly, and the configuration path remained unchanged, as shown in Table 7. Therefore, the robustness of the configurational results can be guaranteed.

Table 7. Configuration of supply chain integration factors.

\begin{tabular}{|c|c|c|c|c|c|}
\hline \multirow{2}{*}{ Condition Variables } & \multicolumn{5}{|c|}{ Supply Chain Integration } \\
\hline & Solution 1 & Solution 2A & Solution 2B & Solution $3 \mathrm{~A}$ & Solution 3B \\
\hline Government policy & $\bullet$ & 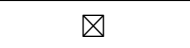 & 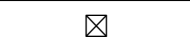 & 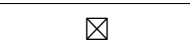 & $\bullet$ \\
\hline Supply chain partnership & $\bigotimes$ & 0 & O & 0 & \\
\hline Information sharing & & & $\bigotimes$ & 0 & \\
\hline Risk aversion & $凶$ & $\bullet$ & & & \\
\hline Degree of intelligence & 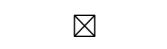 & & $\bullet$ & 凶 & $\bullet$ \\
\hline Consistency & 0.864172 & 0.932552 & 0.906883 & 0.918103 & 0.926126 \\
\hline Original coverage & 0.28536 & 0.446489 & 0.501874 & 0.27208 & 0.30807 \\
\hline Unique coverage & 0.1025214 & 0.040232 & 0.127622 & 0.015642 & 0.027435 \\
\hline Total consistency & & & 0.884623 & & \\
\hline The total coverage & & & 0.720164 & & \\
\hline
\end{tabular}

Note: represents that the core condition exists; $\bigotimes$ represents the absence of a core condition; $\bullet$ represents the existence of marginal conditions; $\square$ represents the absence of marginal conditions; "Blank" indicates that the condition can be present or absent.

\section{Conclusions and Enlightenment}

\subsection{Research Conclusions}

Combining the 185 valid questionnaire survey data of Tianjin manufacturing companies, from the perspective of configuration, based on further stimulation and enhancement of the efficiency of the overall coordination of supply chain system, building the government policy, supply chain partnership, information sharing, risk aversion and intelligent degree, the relationship between the theoretical model reveals the influence of core supply chain integration and also its complex interactive nature. Using the method of fs QCA analyzing the configuration of the above theoretical model, the conclusions are as follows:

(1) Through the fs QCA3.0 software on the analysis of the questionnaire data processing, it was found that the government policy, supply chain partnership, information 
sharing, risk aversion, and intelligent degree of the consistency level is below 0.9 , which shows that the five factors are not the necessary factors to promote the integration of the supply chain, and that validation of manufacturing enterprises in the supply chain integration is a complex process, as no single factor played a significant role. This shows that the effect of manufacturing enterprises' supply chain integration factors alone on supply chain integration is far less than after the configuration of these factors. Each supply chain integration configuration requires the existence of at least one of the core conditional supply chain partnerships or information sharing. The operation results of fs QCA give the configuration of five supply chain integration factors, and the five configuration results forms three supply chain integration paths, and each path promotes the supply chain integration of manufacturing enterprises to the same extent.

(2) Although there are many problems to be solved in the supply chain operation and management of manufacturing enterprises in Tianjin, enterprises have been actively exploring various factors effecting supply chain integration, and some enterprises have gradually launched the integration of the supply chain. This article uses the fuzzy qualitative comparative method to research the supply chain integration path, through the interaction between various factors affecting the manufacturing enterprise supply chain integration mechanism and the configuration of the anatomy, define a "sharing" type, "cooperative" type, " cooperative-sharing type" three supply chains integration path, supply chain partnership and information sharing are the core conditions. The formation of the supply chain partnership can improve the quality and level of enterprise information sharing, and the relationship between information sharing and supply chain integration is mutually promoting and spiraling. Therefore, supply chain partnership and information sharing combined with other integration factors can effectively promote the supply chain integration, thus improving the collaborative efficiency of supply chain.

(3) There are a variety of manufacturing enterprises in China, and different types of manufacturing enterprises have different functional requirements for the supply chain. As an important industrial production base in China, Tianjin has complete industrial product chains, which provide abundant supply chain samples of manufacturing enterprises for research. It is worth mentioning that although the operation results of fs QCA show that the degree of intelligence is not the core condition of supply chain integration at present, with the deepening of the new development pattern of information and digitalization, the intelligent development of manufacturing enterprises in the future is inevitable. Therefore, enterprises should continue to pay attention to the changes in the functional requirements of the supply chain due to the degree of intelligence and update the management mode in time to improve the collaborative development of the supply chain.

\subsection{Practical Enlightenment}

This study provides some practical enlightenment for the supply chain integration of manufacturing enterprises.

(1) Manufacturing enterprises to explore the integration path of the supply chain. Supply chain integration itself is a management method of higher-level cooperation between supply chain partners to provide customers with higher value and improve their competitive advantages [2]. It is a magic weapon for enterprises to obtain greater performance and enhance their competitive advantages. At present, China's manufacturing industry accounts for an increasing proportion in the world, and the demand for supply chain functions is also becoming stronger. Therefore, it is necessary for the manufacturing industry to actively explore the integration path of the supply chain, and continuously improve the management level and collaborative efficiency of the existing supply chain. With the integration of Internet information technology into manufacturing enterprises and the continuous application of the whole supply chain system, the supply chain integration of manufacturing enterprises will be affected by more factors in the future. Therefore, manufacturing enterprises should grasp the current development of the times and constantly arm themselves with new technologies to achieve better development. 
(2) Each subject in the supply chain should attach importance to establishing cooperative partnerships in the process of supply chain integration. Through the operation of fs QCA software, it can be seen that supply chain partnership is one of the core elements in supply chain integration, and supply chain partnership exists in four of the five configuration combinations, indicating the importance of supply chain partnership in supply chain integration. Between different manufacturing companies, to achieve the same business objectives to invest together related resources, to achieve common targets set by the cooperation with each other, make up the supply chain partnership, stable and close relations of cooperation and can improve the level of trust among supply chain partners, increase the number of transactions of upstream and downstream enterprises of the supply chain, improve the efficiency of cooperation. Partnerships between enterprises can improve each other's production efficiency, enhance the ability of enterprises to deal with risks, and promote collaborative development among enterprises. Therefore, a good partnership is not only an effective way to promote supply chain integration, but also an effective means to improve the performance of enterprises.

(3) Supply chain integration can better improve synergistic efficiency among enterprises. The results show that supply chain integration can effectively reduce information asymmetry in supply chain management. By integrating with suppliers and customers, manufacturing enterprises can establish a stable and close supply chain partnership, which can improve cooperation quality and disperse operational risks. In addition, by sharing key resources between the supply chain partners, non-value-added intermediate links can be also reduced, and operating costs can be reduced. At the same time, the establishment of supply chain partnership between enterprises can enhance mutual trust, improve the quality and level of information sharing, effectively reduce the "long whip" problem caused by information asymmetry, improve the overall collaborative efficiency of the supply chain, and enhance the competitive advantage of upstream and downstream enterprises of the supply chain.

\subsection{Research Limitations and Prospects}

(1) Increase research samples. This study used manufacturing supply chains in Tianjin as the research object; although the manufacturing system of Tianjin provided reliable support, the different area government policies involved in the process of manufacturing enterprises, supply chain partnership, information sharing, risk aversion, and intelligent degree of the recognition of the role of supply chain integration may create certain differences. In the future, questionnaires can be further conducted in several different regions to expand the number and scope of research samples and further improve and adjust the existing research conclusions.

(2) Mining and integrating details based on specific cases. In this paper, the fuzzy set qualitative comparative analysis method overcomes the defect of traditional linear regression that can only analyze single influencing factors one by one, and better explains how various factors interact to produce complex effects on the integration of supply chain of manufacturing enterprises, but the study of specific integration details is not deep enough. The subsequent research can theoretically explore the corresponding supply chain of manufacturing enterprises according to the three paths obtained in this paper, explore the different characteristics of traditional supply chain integration path and intelligent supply chain integration path, and discover the driving mechanism of various integration factors in different types of supply chains.

(3) Explore a new supply chain integration path. With the emergence of various emerging technologies, consumer demand for products is increasingly personalized and diversified and is in dynamic change. Therefore, an agile supply chain that can respond to dynamic market demand in real-time arises at the right moment. The traditional supply chain management model has many links and emphasizes post-event control, which easily leads to supply and demand dislocation. An agile supply chain management mode emphasizes the enterprise by optimizing the management structure and the implementa- 
tion process to establish a highly integrated and shared information system, thus giving companies a quick response and the ability to handle customer orders and to streamline the product circulation. This will have a great influence on production, warehousing, distribution and delivery in the supply chain. The emergence of the new supply chain management model may change the driving factors of the existing supply chain integration, thus changing the existing supply chain integration path. Therefore, the impact or change of emerging technologies on supply chain integration deserves further attention and research.

Author Contributions: The contribution of both authors was balanced in all phases of the development of this study, both in the empirical part (creation and validation of the instrument, data collection, and analysis) and in the writing part of this manuscript and its various parts. All authors have read and agreed to the published version of the manuscript.

Funding: This research received no external funding.

Institutional Review Board Statement: Ethical review and approval were waived for this study, as it did not involve personally identifiable or sensitive data.

Informed Consent Statement: The study does not involve human nor sensitive data.

Data Availability Statement: The data in this paper were obtained through a questionnaire survey.

Conflicts of Interest: The authors declare no conflict of interest.

\section{References}

1. $\mathrm{Bu}, \mathrm{M}$. Supply chain integration and retail firm performance: The mediating role of supply chain flexibility. J. Commer. Econ. 2020, 22, 121-124.

2. Flynn, B.B.; Huo, B.; Zhao, X. The impact of supply chain integration on performance: A contingency and configuration approach J. Oper. Manag. 2010, 28, 58-71. [CrossRef]

3. Benton, M.J.M.C. Supply chain partnerships: Opportunities for operations research. Eur. J. Oper. Res. 1997, 101, 419-429.

4. Huo, B.; Ye, Y.; Zhao, X.; Shou, Y. The impact of human capital on supply chain integration and competitive performance. Int. J. Prod. Econ. 2016, 178, 132-143. [CrossRef]

5. Xu, K.; Wang, R.; Zhang, H.; Chen, G. The impact of technological innovation on sustainable development in China's textile and garment industry: A mediating effect model from the perspective of supply chain. J. Stat. Inf. 2015, 30, 65-70.

6. Zeng, M.; Zhu, J. The impact of environmental uncertainty and government support on supply chain integration. Sci. Res. Manag. 2014, 35, 79-86.

7. Pan, A.; Liu, H. An exploratory study on the evolution of relational behavior and organizational knowledge under the culture of rationality. Nankai Bus. Rev. 2015, 18, 85-94.

8. Zhang, W.; Hua, Z.S. Bullwhip effect in multi-product supply chain and its reduction method. J. Syst. Eng. 2010, $25,479-483$.

9. Wang, L.; Li, D. Study on supply chain integration and financial performance of manufacturing enterprises. J. Southeast Univ. (Philos. Soc. Sci.) 2016, 18, 55-57.

10. Huo, Y.; Wang, H.; Qi, E. Building smart logistics and supply chain to help smart manufacturing-Introduction of smart logistics and smart supply chain. China Mech. Eng. 2020, 31, 2891-2897.

11. Chen, X. A review of supply chain integration research. China Water Transp. (Acad. Version) 2007, 11, 247-250.

12. Xu, K.; Dong, Y.; Evers, P.T. Towards better coordination of the supply chain. Transp. Res. E 2001, 37, 35-54. [CrossRef]

13. Zhou, S.; Wan, G. The impact of information technology capabilities on supply chain performance: Based on the perspective of information integration. J. Syst. Manag. 2016, 25, 90-102.

14. Balsmeier, P.W.; Voisin, W.J. Supply chain management: A time- based strategy. Ind. Manag. 1996, 9, $24-27$.

15. Kang, S.B.; Moon, T. Impact of information exchange and supply chain integration on supply chain performance. Sci. Technol. 2016, 9, 237-246. [CrossRef]

16. Yu, J.; You, D. Comparative study of supply chain competition and cooperation mode considering the characteristics of risk aversion. Syst. Eng.-Theory Pract. 2019, 39, 2091-2104.

17. Wu, Q.; Zhang, Y. Performance analysis of commercial circulation enterprises based on supply chain risk management. J. Commer. Econ. 2020, 24, 114-116.

18. Weingarten, F.; Humphreys, P.; Gimenez, C.; McIvor, R. Risk, risk management practices, and the success of supply chain integration. Int. J. Prod. Econ. 2016, 171, 361-370. [CrossRef]

19. Roh, J.; Hong, P.; Min, H. Implementation of a responsive supply chain strategy in global complexity: The case of manufacturing firms. Int. J. Prod. Econ. 2014, 147, 198-210. [CrossRef]

20. Zhou, J.; Yao, X. Advanced manufacturing technology and the new industrial revolution. Comput. Integr. Manuf. Syst. 2015, 21, 1963-1978. 
21. Barton, R.; Thomas, A. Implementation of intelligent systems, enabling integration of SMEs to high-value supply chain networks. Eng. Appl. Artif. Intell. 2009, 22, 929-938. [CrossRef]

22. Huo, B.; Han, Z.; Zhao, X. The impact of power and relationship commitment on supplier integration. J. Manag. Sci. China 2013, $16,33-50$.

23. Zeng, M.; Lu, S.; Wu, Q. Research on the relationship between government support, trust and supply chain external integration. Chin. J. Manag. Sci. 2014, 22, 48-55.

24. Sheng, S.; Zhou, K.Z.; Li, J.J. The effects of business and political ties on firm performance: Evidence from China. J. Mark. 2011, 75, 1-15. [CrossRef]

25. Dou, C.; Chen, X.; Li, X. Government-backed customers, market perception and investment opportunities: From the perspective of supply chain integration. Manag. Rev. 2020, 32, 13-28.

26. Liu, H.; Wang, Y.; Li, H. Research on the relationship between partnership, logistics capability and supply chain integration. Chin. J. Manag. Sci. 2016, 24, 148-157.

27. Ye, F.; Xu, X. Research on the relationship between partner characteristics, partnership, and information sharing in the supply chain. J. Manag. Sci. China 2009, 12, 115-128.

28. Feng, H.; Shi, Y.; Wei, J. A study on the interaction between social control and supply chain performance: Dependence and supply chain integration as mediators. Chin. J. Manag. Sci. 2020, 28, 136-145.

29. Fiss, P.C. A set-theoretic approach to organizational configurations. Acad. Manag. Rev. 2007, 32, 1180-1198. [CrossRef]

30. Cai, S.; Jun, M.; Yang, Z. Implementing supply chain information integration in China: The role of institutional forces and trust. J. Oper. Manag. 2010, 28, 257-268. [CrossRef]

31. Chen, Y.R.; Yang, C.; Hsu, S.M.; Wang, Y.D. Entry mode choice in China's regional distribution markets: Institution vs. transaction costs perspectives. Ind. Mark. Manag. 2009, 38, 702-713. [CrossRef]

32. Morgan, R.M.; Hunt, S.D. The commitment-trust theory of relationship marketing. J. Mark. 1994, 58, 20-38. [CrossRef]

33. Kumar, K.; Dissel, H.G.V. Sustainable collaboration: Managing conflict and cooperation in interorganizational systems. MIS Q. 1996, 20, 279-300. [CrossRef]

34. Li, M. The Road to Total Risk Management: Theory and Practice Insight of Risk Management; China Financial Publishing House: Beijing, China, 2014.

35. Yan, C. Fundamental Knowledge of Risk Management; Economy \& Management Publishing House: Beijing, China, 2018.

36. Meng, F.; Zhao, G. Study on the influencing factors of the development from traditional manufacturing to intelligent manufacturing. Sci. Technol. Prog. Policy 2018, 35, 66-72.

37. Guo, Z. Social Statistical Analysis Method-Application of SPSS Software; China Renmin University Press: Beijing, China, 1999.

38. Gefen, D.; Straub, D.W.; Boudreau, M. Structural equation modeling and regression: Guidelines for research practice. Commun. Assoc. Inf. Syst. 2010, 4, 1-78. [CrossRef]

39. Joseph, F.; Hair, J.R.; Anderson, R.E.; Tatham, R.L.; Black, W.C. Multivariate Date Analysis with Reading, 4th ed.; Prentice-Hall International: Upper Saddle River, NJ, USA, 1995.

40. Schwarzwald, J.; Weisenberg, M.; Solomon, Z. Factor invariance of SCL-90-R: The case of combat stress reaction. Psychol. Assess. 1991, 3, 385-390. [CrossRef]

41. Alem, A.; Kebede, D.; Woldesemaiat, G.; Jacobsson, L.; Kullgren, G. The prevalence and socio-demographic correlates of mental distress in Buiajira Ethiopia. Acta Psychiatr. Scand. 1999, 100, 48-55. [CrossRef]

42. McEachan RR, C.; Conner, M.; Taylor, N.J.; Lawton, R.J. Prospective prediction of health-related behaviours with the theory of planned behaviour: A meta-analysis. Health Psychol. Rev. 2011, 5, 97-144. [CrossRef]

43. Ragin, C.C. Research on Redesign of Social Sciences; Machinery Industry Press: Beijing, China, 2019; p. 48.

44. Ragin, C.C. Redesigning Social Inquiry: Fuzzy Sets and Beyond; University of Chicago Press: Chicago, IL, USA, 2008.

45. Fiss, P.C. Building better causal theories: A fuzzy set approach to typologies in organization research. Acad. Manag. J. 2011, 54, 393-420. [CrossRef]

46. Du, Y.; Jia, L. Configuration perspective and qualitative comparative analysis (QCA): A new approach to management research. Manag. World 2017, 155-167.

47. Rigby, D.K.; Buchanan, W.T. Putting more strategy into strategic alliances. Dir. Boards 1994, 18, 14-19.

48. Li, S.; Lin, B. Accessing information sharing and information quality in supply chain management. Decis. Support Syst. 2007, 42, 1641-1656. [CrossRef] 